\title{
GÊNERO, FLEXIBILIDADE E PRECARIZAÇÃO: o trabalho a domicílio na indústria de confecções
}

\author{
Magda de Almeida Neves* \\ Célia Maria Pedrosa**
}

\begin{abstract}
Resumo: O rápido processo de mudanças na economia global, nos últimos anos, e a reestruturação produtiva reconfiguraram as relações de gênero no trabalho. A entrada cada vez maior do contingente feminino no mercado de trabalho, além de dar visibilidade às relações que se engendram na esfera privada, apresenta um conjunto de novas experiências vivenciadas pelas mulheres no local de trabalho e no contexto mais amplo da própria sociedade. Nestes últimos anos, a dinâmica flexível do processo produtivo acarretou o crescimento significativo do trabalho informal, num processo caracterizado pela sua heterogeneidade e, também, pela forma sistêmica de interação entre o setor formal e o informal. $\mathrm{O}$ objetivo do presente artigo é analisar o trabalho a domicílio realizado por mulheres para a indústria de confecção numa cidade de porte médio em Minas Gerais. $\mathrm{O}$ enfraquecimento da regulação do trabalho e dos direitos sociais possibilita a multiplicação de atividades precarizadas, gerando flexibilização do contrato de trabalho, das condições de trabalho, da jornada de trabalho e uma extensão/interação entre espaço privado/ doméstico e espaço econômico/produtivo.
\end{abstract}

Palavras-chave: relações de gênero, reestruturação produtiva, flexiblidade, precarização.

\footnotetext{
* Doutora em Sociologia; professora do Programa de Pós-graduação em Ciências Sociais (Mestrado e Doutorado) da PUC Minas e pesquisadora do IRT/PUC Minas. E-mail: mneves@pucminas.br

** Mestre em Ciências Sociais: Gestão de Cidades/PUC Minas; professora da Fundação Educacional de Divinópolis/MG (FUNED). E-mail: celia_cmp@ig.com.br
} 
Nas últimas décadas, o processo de globalização, as políticas de cunho neo-liberal e a reestruturação produtiva transformaram não só a inserção dos trabalhadores no mundo do trabalho, mas também a forma e o conteúdo do trabalho (Neves, 2004).

Como conseqüência dos processos de reestruturação produtiva, os novos padrões de gestão do trabalho desenvolveramse sustentados, centralmente, na flexibilização. Desta maneira, ocorreu uma crescente transformação do contrato trabalhista, demonstrada nas diversas formas flexíveis do emprego e do mercado de trabalho. Estas práticas assumem diferentes configurações, como: a terceirização, o emprego temporário, a subcontratação, a informalidade, as cooperativas de trabalho, as atividades autônomas e inúmeras formas de trabalho assalariado disfarçado. De acordo com Druck (2002, p. 13), "a hegemonia da lógica financeira exige maior mobilidade para os capitais e processos produtivos menos rígidos e cada vez mais flexíveis, objetivando investimentos e resultados de curto prazo".

De acordo com Robert Castel, a precarização é um processo central comandado pelas novas exigências tecnológicas e econômicas da evolução do capitalismo moderno. O autor chama a atenção para três aspectos importantes desta nova dinâmica do capital: a desestabilização dos estáveis, a instalação na precariedade de diferentes trabalhadores, e o aumento do desemprego.

Para Castel (1998), há um déficit de lugares ocupáveis na estrutura social, impedindo muitos jovens de entrarem no mercado de trabalho. Ainda segundo o autor, a insegurança no emprego ou sua precarização devem ser considerados como um processo importante, pois aparece como causa direta da vulnerabilidade social, mais do que um handicap exclusivamente econômico, e, por isso do desemprego e da desfiliação social. Portanto, a precarização pode ser percebida como institucionalização de duas formas: precarização econômica 
- das estruturas produtivas e salariais - e precarização da proteção social, isto é, da legislação relativa aos direitos trabalhistas.

Analisando estudos e pesquisas realizadas na França, Hirata e Préteceille (2002) chamam a atenção para a diversidade e a complexidade de problemas decorrentes da flexibilidade e da precarização do trabalho, para além da fragilização do emprego. Para os autores, a dupla transformação do trabalho - tanto em relação ao conteúdo da atividade quanto às formas de emprego -, demonstra a importância de se analisar a organização do trabalho e o mercado de trabalho. De um lado, os novos modelos de gestão exigem por parte do trabalhador maior qualificação e envolvimento no processo de trabalho, requerendo autonomia, iniciativa, responsabilidade e comunicação. De outro lado, os vínculos com o emprego tornam-se cada vez mais precários e flexíveis, acarretando instabilidade para um grande número de assalariados.

\section{A precarização do trabalho feminino no contexto da reestruturação produtiva}

Em geral, as novas tendências organizacionais baseadas na flexibilidade, além de significarem uma resposta à crise do fordismo nos anos 70, procuraram atender às exigências das novas tecnologias fundadas na microeletrônica, da mesma forma como as inovações tayloristas/fordistas também visavam atender às novas tecnologias da época. Mas, no caso brasileiro, alguns autores como Borges e Druck (2002) entendem que a reestruturação industrial tem se pautado mais por novos processos organizacionais do que por inovações tecnológicas. Focada na desconcentração, flexibilidade e redução de custos, a marca da reestruturação brasileira tem sido a terceirização.

Segundo Abramo (1998), na América Latina prevalece a formação de cadeias produtivas mais próximas do modelo japonês, 
caracterizado pela grande assimetria de poder entre as empresas e fragilidade nas relações de trabalho. Neste contexto ocorrem novos processos de segmentação do trabalho e de precarização do trabalho feminino. As hierarquias que se formam nessas cadeias não ocorrem apenas em nível de poder e subordinação empresarial, mas, também, em nível de condições de trabalho. Os trabalhadores diretos da empresa que estão no topo possuem direitos sociais que vão se reduzindo ao longo da cadeia, caracterizando-se sua ponta, na maioria das vezes, pelo trabalho socialmente desprotegido.

Vários estudos a este respeito têm apontado para o aumento da participação das mulheres, cujo trabalho tem se concentrado na ponta da cadeia com acentuada precariedade, caracterizando-se também pela combinação de uma ampla variedade de condições de trabalho com níveis bastante diferenciados de qualidade, remuneração e estabilidade, e, mais uma vez, com uma pronunciada divisão sexual do trabalho (Abramo, 1998; Hirata, 1998; Neves, 2000; Leite, 2004).

No Brasil, os dados do IBGE/Pnad demonstram a crescente participação feminina na População Economicamente Ativa (PEA), com uma relativa redução da participação masculina. Em 1976, a participação feminina na PEA era de 28,2\%; em 2002, este número se elevou para $42,5 \%$. Contudo, se a participação feminina na PEA foi substancial, indicando um crescimento de 47,56\% entre 1976 e 2002, o mesmo não ocorreu quanto ao crescimento das mulheres no conjunto dos empregados. Em 1976, sua participação era de 30,3\% e, em 2002, de 35,8\%, indicando um crescimento de apenas $18,15 \%$ nesse período. Estes dados são indicativos de que os processos de reestruturação produtiva têm ampliado a participação da mulher no mercado de trabalho, contudo, esta inserção não tem ocorrido na forma do emprego formal, mas em atividades informais e precárias.

Outro dado significativo de discriminação sexual refere-se à remuneração. O percentual de mulheres que recebem as menores 
faixas salariais (até 2 salários mínimos) é superior ao dos homens, sendo que o percentual de homens que recebem as maiores faixas salariais (mais de 10 salários mínimos) é superior ao das mulheres. Por sua vez, o número de mulheres que não possuem rendimentos é superior ao dos homens.

A maior inserção da mulher no mercado de trabalho também não significa uma distribuição mais eqüitativa dos afazeres domésticos; as mulheres continuam dedicando maior tempo a estas atividades do que os homens. Esse papel feminino, de responsável pelas tarefas domésticas, construído culturalmente, tem sido utilizado como argumento para a precarização do trabalho feminino, mediante a contratação de mulheres com jornada de trabalho parcial e salário reduzido.

Neves (2001), ao analisar a reestruturação da cadeia produtiva da FIAT em Betim (MG), concluiu que os processos de reestruturação adotados por essa empresa constituem uma cadeia de subcontratação, que concentra trabalhadores jovens com maior escolaridade e do sexo masculino na montadora. Por outro lado, as empresas situadas nos níveis mais baixos da cadeia produtiva, que exercem atividades com menor exigência tecnológica, concentram maior número de trabalhadoras. Nesse estudo, a autora também confirma que o processo de reestruturação produtiva e de mudanças tecnológicas não modificou as formas de inserção de homens e mulheres no mercado de trabalho. Ao contrário, reforçou as situações históricas de subordinação da mulher na sociedade.

As formas de inserção de homens e mulheres no mercado de trabalho revelam as representações sobre o gênero masculino e feminino construídos culturalmente, ou seja, essas representações culturais são a base da divisão sexual do trabalho, "estabelecendo 'os lugares' a que estão destinados homens e mulheres desde a inserção no mercado de trabalho, as estratégias de qualificação e os postos de trabalho a serem ocupados" (Neves, 2001, p. 107). 


\section{A informalidade no contexto da reestruturação produtiva}

A informalidade éum fenômeno inerente ao sistema capitalista, sendo sua conceituação complexa, uma vez que envolve várias situações. Uma de suas definições decorre de um estudo realizado no final dos anos 60 pela OIT (Organização Internacional do Trabalho), relacionando informalidade ao desenvolvimento econômico. Nesse estudo, a informalidade estava associada aos processos de êxodo rural não suportados em sua totalidade pela economia formal urbana, ou seja, os trabalhadores que migravam para as cidades não eram absorvidos em sua totalidade pela economia urbana, levando ao crescimento da informalidade. A formulação deste conceito se justificava pelo contexto da época, marcada pela intensa migração de população rural para as cidades nos países que se encontravam em processo de industrialização. Contudo, essa definição apresenta limitações pelo fato de a informalidade ser pensada somente sob o ponto de vista do desenvolvimento dos países em processos de industrialização, em uma visão dualista que separa economia rural e urbana, deixando de considerar as dinâmicas excludentes do processo de produção capitalista (Figueiras, Druck, Amaral, 2004).

Ainda de acordo com Amaral, Druck e Filgueiras (2004) em meados dos anos 70, passou-se a analisar a informalidade associada a atividades não capitalistas, ou seja, aquelas que não se sustentam a partir da geração da mais-valia, nem pela separação entre o capital e trabalho. Os exemplos mais comuns seriam os trabalhadores por conta própria e as economias familiares - segmentos que se desenvolvem subordinados aos processos mais gerais do capitalismo, e que se contraem ou expandem conforme o ciclo econômico. Entendem esses autores que este conceito de informalidade rompe com a teoria dual estática presente no conceito anterior, que dividia a economia em dois setores independentes entre si - o moderno e o tradicional e não refletia a complexidade da dinâmica do processo de produção e emprego. Neste segundo conceito, a informalidade passou a ser 
pensada no contexto dos processos mais gerais de acumulação capitalista, embora mantendo ainda uma certa dualidade, por separar o setor formal e legal do informal e ilegal.

Os processos de reestruturação produtiva exigem uma maior reflexão acerca da informalidade, porque esta apresenta forte tendência à expansão diante da adoção de processos produtivos pautados pela flexibilidade e precarização do trabalho. Neste contexto, a informalidade passa a ser compreendida não apenas em decorrência do êxodo rural ou de traços intrínsecos da economia de subsistência, ou de um exército industrial de reserva diante de uma sociedade predominantemente salarial.

Um estudo de Ulyssea (2005) aponta para um crescimento da informalidade do trabalho na década de 1990, depois de um período de estabilidade entre 1983 e 1989. Segundo este autor, nos anos de 1983/89, a Pnad, apresentou a informalidade com pouca alteração, permanecendo nos níveis próximos de $28 \%$ da população ocupada. Mas, ao final da década de 1990 ela alcançou o percentual de 38\%. O fato da informalidade alcançar, na década de 1990, níveis superiores aos do início dos anos de 1980, que foram marcados por uma forte crise econômica, é um indicativo de que este fenômeno está assumindo um caráter estrutural e não conjuntural.

Dessa forma, a informalidade passa a ser analisada a partir das novas dinâmicas da reestruturação produtiva do capital, tratando-se de um fenômeno em expansão, que envolve tanto os países centrais quanto os periféricos. A informalidade deixa de se referir somente à economia ilegal ou não registrada para fazer parte também da estrutura produtiva dos mercados formais através dos processos de flexibilização. São conseqüências da adoção de modelos de empresas enxutas e se expressam através dos terceirizados, trabalhadores temporários, autônomos e também pelo trabalho a domicílio. Envolvem tanto trabalhadores qualificados quanto desqualificados, com altas ou baixas remunerações. Também para Lautier (1994), 
não é possível separar formal e informal em dois setores distintos, já que dentro de uma mesma empresa, pode existir interseção entre atividades formais e informais. Neste caso o setor informal seria um subconjunto do setor institucional, formalizado, como também salienta Charmes (1997).

Segundo Carvalho, Neves e Jayme (1992), não se trata apenas de analisar se uma atividade é transferida do formal ao informal, e sim de estabelecer como certas atividades formais e informais estão interligadas e até mesmo apresentam variados graus de interdependência, formando assim uma conexão sistêmica com a economia formal.

Para uma melhor compreensão desta relação é importante salientar três aspectos comuns nas economias informais: a conexão sistêmica com a economia formal, as características especiais do trabalho empregado nas atividades informais, e as atitudes do governo em direção à não regulação do setor.

\section{A informalidade no contexto do trabalho domiciliar da indústria de confecção}

De forma genérica, pode-se conceituar o trabalho domiciliar como atividade remunerada exercida no espaço de moradia de quem o realiza. Assumem as formas assalariadas ou por conta própria, podendo o trabalhador realizar todo o processo produtivo ou apenas uma de suas etapas.

A reestruturação produtiva, ao utilizar-se da informalidade, está expandindo o trabalho domiciliar, cuja desintegração se processou com o advento da indústria moderna, mas que retorna na atualidade. Embora este fenômeno possa parecer paradoxal, ele encontra-se coerente com as novas tendências de gestão de trabalho pautadas pela flexibilidade e precariedade. 
Em geral, o trabalho domiciliar encontra-se inserido nas pontas das cadeias produtivas, algumas de extensão internacional, envolvendo grandes empresas que buscam, conforme Lavinas e Sorj (2000, p. 235), tirar "proveito, seja das competências de trabalhadores em diferentes regiões do mundo, seja de menores níveis de remuneração".

Essa atividade produtiva é utilizada de duas formas: uma envolvendo a contratação assalariada formal, e a outra, o trabalho informal na condição de autônomo, sendo remunerado somente pelas tarefas realizadas.

A ausência do reconhecimento do vínculo empregatício tem sido um dos motivos da expansão do trabalho domiciliar. Segundo Lorena H. Silva, esta modalidade de trabalho tem sido caracterizada por:

a) sonegação dos benefícios e direitos assegurados pela legislação aos trabalhadores;

b) intensificação do trabalho e extensão da jornada para que possam cumprir os prazos contratados;

d) irregularidade dos rendimentos devido à demanda variável de trabalho;

e) pequena ou nula capacidade de negociação com os contratantes em decorrência da dispersão e inexistência de contatos entre os trabalhadores contratados, tornando difícil ou inviável qualquer forma de organização e atuação coletiva;

f) difícil registro fidedigno de sua magnitude devido a seu caráter oculto ou invisível;

g) utilização predominantemente de mão-de-obra feminina. (Silva, 2001, p. 276).

$\mathrm{Na}$ indústria de confecção, a adoção de processo de terceirizaçâo faz parte da reestruturação do setor, buscando torná-lo 
mais competitivo, diante das dificuldades com a concorrência estrangeira no início da abertura comercial nos anos de 1990. As formas de reestruturação na indústria de confecção utilizam-se pouco de novas tecnologias, tendo se pautado mais pela descentralização e flexibilização da produção com o objetivo de reduzir custos, especialmente os encargos sociais, sem maiores preocupações com a qualidade. Outro aspecto que favorece os processos de terceirizações refere-se à sazonalidade da produção, com picos nos períodos que antecedem o inverno e o Natal, épocas em que os empresários são levados a subcontratarem.

A terceirização da costura, na indústria da confecção, reforça uma discriminação histórica no processo de inserção da mulher no mercado de trabalho. Leite (2004, p. 13) indica que já em 1999 havia, nesse setor, relativamente mais mulheres sem carteira assinada do que homens, ou seja, do total de homens que trabalhavam na indústria têxtil e do vestuário, 29,6\% não possuíam carteira assinada, contra $70,4 \%$ de mulheres na mesma condição. Da mesma forma que $30,8 \%$ dos homens deste segmento trabalhavam por conta própria, contra $69,2 \%$ de mulheres. Salienta ainda a autora, a maior concentração de mão-de-obra feminina nas empresas de menor porte (até 19 empregados), representando $74,7 \%$ do total dos trabalhadores, enquanto nas empresas de maior porte (500 empregados ou mais), elas representam apenas $45,7 \%$ do conjunto dos trabalhadores. Outro dado importante, que confirma uma discriminação histórica, refere-se ao fato de as mulheres receberem remuneração inferior à que é paga aos homens. Na indústria têxtil e da confecção também prevalece esta situação, e, em 2002, enquanto a média salarial masculina era de $\mathrm{R} \$ 698,17$, a feminina era de $\mathrm{R} \$ 421,98$.

Abreu e Sorj (1993, p. 61), ao estudarem o trabalho domiciliar inserido no contexto da indústria da confecção do Rio de Janeiro, 
apontaram alguns resultados que podem ser paradigmáticos neste tipo de trabalho. Para estas autoras, o trabalho realizado no domicílio pelas costureiras terceirizadas está envolto ao papel que a mulher desempenha enquanto mãe, esposa e dona-de-casa, uma vez que permite que a trabalhadora realize tarefas ao longo do dia, em uma exaustiva jornada que tanto é força de trabalho quanto reprodutora da força de trabalho, na medida em que garante as condições necessárias para que os demais trabalhadores externos retornem ao trabalho. O espaço do trabalho é o espaço da família, está disperso por toda a cidade, fora dos limites da empresa e dentro dos limites da casa.

Para essas autoras, há uma fraca identidade profissional para as trabalhadoras, uma vez que não há uma nítida divisão entre os afazeres domésticos e o trabalho profissional. Isso faz com que o trabalho profissional torne-se domesticado, sem uma avaliação de custo e benefício, sem possibilidades de carreira ou promoção as costureiras ficam excluídas dos benefícios sociais. Neste contexto, essas mulheres encontrem grandes dificuldades para diferenciar a sua identidade profissional daquela de mãe e esposa (Abreu, Sorj, 1993).

Em pesquisa realizada na região de Campinas, sobre redes de subcontratação e trabalho a domicílio na indústria de confecção, Araújo e Amorim (2002) verificaram, na cadeia produtiva do trabalho, que as costureiras a domicílio estão totalmente subordinadas às condições, prazos, formas de pagamento e impostos, mas numa relação de trabalho precarizada, estabelecida informalmente para escapar da regulamentação e dos encargos legais. As autoras chamam a atenção para a exploração do trabalho feminino na cadeia produtiva que ocorre de forma invisível, pois não constam dos registros oficiais das empresas e nem das estatísticas oficiais. 


\section{O trabalho a domicílio na indústria de confecção}

A pesquisa realizada na indústria de confecção em Divinópolis, cidade de médio porte de Minas Gerais que, tendo 183.962 habitantes em 2002, apresentou diversos fatores já constatados em investigações realizadas no mesmo setor e discutidas anteriormente. Neste estudo foi realizado um levantamento com os empresários deste segmento industrial, envolvendo 65 empresas de confecção. Embora apenas 38,5\% dos empresários entrevistados tenham afirmado que terceirizam a costura, esta tarefa representa a maior parte da força de trabalho de uma confecção (Pedrosa, 2005) e a sua terceirização significa a dispensa da grande maioria dos trabalhadores diretos, devendo ser considerado, ainda, que este número aumentará devido ao fato de muitos entrevistados terem afirmado que pretendem subcontratar costureiras. Ressalte-se que, em 2002, o número de trabalhadores formais deste segmento, segundo a RAIS, já havia sido reduzido para $41,79 \%$, de $45 \%$ em 2000 .

O trabalho terceirizado, domiciliar e informal também está sendo adotado pela indústria de confecção de Divinópolis, como estratégia de reestruturação, visando à redução de custos, o que vem sendo apontado na literatura como uma tendência geral deste segmento no Brasil. A formação de cadeias a partir da desconcentração produtiva na indústria da confecção de Divinópolis não elimina as características tayloristas em seu processo de trabalho. Permanece a rígida divisão do trabalho, a especialização e repetição de tarefas e pouca qualificação do trabalhador em quase todas as etapas da produção, com exceção da parte de criação. A concepção do produto, que se realiza através da criação de modelos, juntamente com os moldes, o infesto e o corte continuam sendo realizados diretamente pela maior parte das empresas. Os moldes são terceirizados somente quando se trata de produção padronizada, a exemplo de moldes de camisas masculinas, que são elaborados por sistemas computadorizados e adquiridos de São Paulo. As etapas 
da produção que estão sendo terceirizadas referem-se à estamparia, acabamento e costura, sendo caracterizadas como repetitivas. Neste sentido, o taylorismo é mantido ao longo da cadeia produtiva, separando-se o processo de concepção no topo e a execução nas demais unidades.

O trabalho de costura e acabamento, quando terceirizado, é realizado por facções. $\mathrm{Na}$ indústria da confecção, facção referese ao trabalho informal e precário de costureiras domiciliares. Por ser informal, não se tem o exato número de facções presentes na indústria da confecção de Divinópolis. Uma pesquisa realizada pelo Instituto Centro de Capacitação e Apoio ao Empreendedor (Iccpe), em 2000, estimou seu número em 1.500 unidades. Além da pesquisa com o empresariado do setor, foram realizadas entrevistas com dez faccionistas escolhidas aleatoriamente na cidade. A apresentação do perfil de cada uma destas trabalhadoras é de fundamental importância para os objetivos a que se propõe este artigo:

Costureira 1 - 30 anos, é casada e tem dois filhos: um com 9 anos de idade e outro com 2 anos. Não concluiu o ensino fundamental. Antes de trabalhar em sua casa, possuía emprego formal em uma fábrica. Embora sua jornada de trabalho seja indefinida, nas épocas de pico, trabalha, em média, 12 horas por dia e conta com a ajuda de sua filha de 9 anos. Sua renda média é de R\$500,00 por mês.

Costureira 2 - 37 anos, é casada, tem dois filhos: uma filha com 15 anos de idade e um filho com 2 anos. Não concluiu o ensino fundamental. Antes de trabalhar em sua casa, possuía emprego formal em uma fábrica. Presta serviços apenas para uma fábrica. Em geral trabalha sozinha, de forma intermitente. Nos períodos de pico, contrata algumas auxiliares sem o registro de carteira de trabalho. Sua renda média é de R\$300,00 e afirmou que recebia mais quando trabalhava em fábrica, mas, com o nascimento da filha, se viu obrigada a trabalhar em casa. 
Costureira 3-42 anos, é casada e tem três filhos adolescentes. Sua formação escolar é $1^{\circ}$ grau incompleto. Antes de trabalhar em sua casa, possuía emprego formal como balconista de uma fábrica. Afirmou que ingressou no trabalho domiciliar porque tornou-se difícil conseguir emprego aos 37 anos, quando foi despedida da fábrica onde trabalhava. Sua jornada de trabalho é de 8 horas por dia e os serviços domésticos são realizados pelos filhos. Sua renda mensal é de R \$600,00, mas afirmou que não pode contar com este dinheiro durante o ano todo, uma vez que trabalha mais no início e final de ano.

Costureira 4- 48 anos, é casada e tem três filhos, sendo dois adolescentes e uma filha adulta e já casada. Não concluiu o ensino fundamental. Antes de trabalhar em sua casa, possuía emprego formal como costureira de uma fábrica. Acha o atual trabalho muito ruim, porque a renda é menor, a jornada de trabalho é maior e não possui direitos trabalhistas. Trabalha com três máquinas, as quais são responsáveis pelo aumento na conta de energia elétrica. Acha seu trabalho solitário e repetitivo. Os preços das peças são determinados pelo tomador de serviços e sua renda média é de $\mathrm{R} \$ 450,00$ por mês. Além do trabalho como costureira, realiza os serviços domésticos e cuida de um neto, para que sua filha possa trabalhar em uma fábrica.

Costureira 5 - 40 anos, é solteira e não tem filhos. Não concluiu o ensino fundamental. Antes de trabalhar em sua casa, possuía emprego formal como costureira de uma fábrica. Sua renda mensal é de, aproximadamente, R\$ 600,00. Realiza o trabalho de facção juntamente com duas irmãs, sendo que nenhuma delas possui registro na carteira de trabalho. A jornada de trabalho é de 12 horas por dia, podendo aumentar nos períodos de pico.

Costureira 6 - 38 anos, é casada e tem dois filhos, ainda crianças. Não concluiu o ensino fundamental. Antes de trabalhar em 
sua casa, possuía emprego formal como costureira de uma fábrica, mas preferiu trabalhar em casa, quando o segundo filho nasceu. Recebe em média $\mathrm{R} \$ 400,00$ mensais e há períodos em que fica sem trabalho e sem renda. Ela acha que esta é a melhor maneira de uma mulher com pouca instrução e com filhos trabalhar, uma vez que não compensa deixar a casa e os filhos para trabalhar fora, com um salário baixo.

Costureira 7-40 anos, é solteira e não tem filhos. Não concluiu o ensino fundamental. Diferentemente das demais costureiras, organiza seu trabalho fora do contexto doméstico, embora em um espaço ligado à sua casa. Possui uma jornada diária de 10 horas e uma renda média mensal de $\mathrm{R} \$ 600,00$. Nas épocas de maior quantidade de trabalho, contrata empregadas sem registro na carteira.

Costureira 8-39 anos, é casada, e tem 3 filhos adolescentes. Não concluiu o ensino fundamental. Não possuía outra atividade remunerada antes de trabalhar como costureira faccionista. Para esta costureira, o trabalho remunerado só foi possível quando os filhos cresceram e passaram a depender menos de seus cuidados. Não soube informar sua remuneração, nem sua jornada de trabalho.

Costureira 9-38 anos, é casada e tem 3 filhos. Não concluiu o ensino fundamental. Casou-se ainda bastante jovem e as tarefas domésticas impediram-na de adquirir uma profissão. Por esta razão, não possuía outra atividade remunerada antes de se tornar costureira e aprendeu este trabalho quando ajudava uma vizinha que também é faccionista. Possui uma jornada diária de 14 horas, que é intercalada com o trabalho doméstico, mas afirma que em determinados períodos suas atividades se estendem "até a madrugada". Possui uma renda média mensal de $\mathrm{R} \$ 600,00$, trabalha sozinha e, eventualmente, conta com a ajuda dos filhos.

Costureira 10 - 41 anos, é casada e tem 4 filhos. Não concluiu o ensino fundamental. Iniciou o trabalho como costureira faccionista 
após a invalidez do marido, por causa da redução da renda familiar. Aprendeu a costurar com algumas amigas. Trabalha em média 10 horas por dia e divide tanto as tarefas domésticas quanto as de faccionista com os filhos e marido. Não soube informar sua renda, mas afirma que é pequena, mas não consegue outro trabalho, devido à ausência de qualificação.

Embora o trabalho de cada uma dessas mulheres seja discreto e silencioso, realizado na privacidade de suas casas, as faccionistas podem ser localizadas com certa facilidade, na periferia da cidade, em bairros cujos moradores são de baixa renda, sendo comum encontrar uma ou duas costureiras em um único quarteirão. Verificou-se, durante o levantamento de dados, um certo receio no fornecimento das informações, especialmente quando indagadas sobre o número de pessoas que com elas trabalham, o que pareceu um temor pela fiscalização tributária.

As costureiras faccionistas, como já ficou evidenciado, são mulheres. Têm em comum o fato de serem casadas, possuírem filhos e algumas até netos, sendo que suas idades variam entre 30 e 50 anos. Dentre as entrevistadas, apenas duas permaneciam no estado civil de solteiras e não possuíam filhos. Este perfil coincide com o das mulheres que realizam costuras domiciliares no Rio de Janeiro, conforme estudo de caso realizado por Abreu e Sorj (1993), para as quais este perfil parece ser o preferencial dos empresários, pelo fato de representarem maior estabilidade do que as solteiras, que buscam melhores oportunidades de emprego.

Nenhuma das costureiras entrevistadas concluiu o ensino fundamental, sendo trabalhadoras com baixa escolaridade, o que evidencia duas formas de exclusão que se relacionam: a exclusão educacional e a de direitos previstos na legislação trabalhista.

Possuem entre três e cinco máquinas de costura, sendo que algumas costureiras afirmaram que, nos períodos de maior 
intensidade de trabalho, o marido e os filhos colaboram no trabalho. Além da família, algumas relataram que, em épocas de pico, nos períodos que antecedem o inverno e o final de ano, subcontratam outras companheiras, sem qualquer registro de carteira de trabalho, caracterizando o que tem sido chamado de quarteirização.

Estas características do trabalho domiciliar apontam outras duas situações graves. A primeira refere-se ao envolvimento dos filhos no trabalho, indicando a possibilidade de utilização do trabalho infantil, que implica prejuízos à infância e à educação escolar. A segunda situação grave refere-se à sazonalidade do trabalho, que gera a insegurança quanto à renda e à própria sobrevivência, fazendo com que estas trabalhadoras tenham que viver do que ganham a cada dia, sem maiores projetos. Quando indagadas sobre a renda, quase todas as entrevistadas tiveram dificuldades para responder.

Ainda que com certa dificuldade, foi possível verificar que seus rendimentos variam entre um e dois salários mínimos, havendo períodos em que ficam sem trabalho e sem renda. Esta situação de descontinuidade do trabalho e de dependentes das conjunturas que o determinam foi também verificada por Leite (2004). Também admitem que este valor não leva em consideração que alguns gastos domésticos aumentaram após ingressarem neste tipo de trabalho, como a energia elétrica e telefone.

Além destes gastos, as faccionistas ainda assumem os prejuízos quanto às eventuais peças que são danificadas. $\mathrm{O}$ preço do trabalho é determinado pelo tomador de serviços, o que demonstra uma clara hierarquia nas relações entre as costureiras e as fábricas tomadoras do serviço. Esta situação é típica das cadeias produtivas que predominam na América Latina, marcadas pela assimetria, decisões unilaterais, fragilidade das relações e a precarização do trabalho feminino. O poder oligopsônico das empresas tomadoras de serviço fica evidenciado, pois, apesar de não se saber o número 
exato de faccionistas, estas existem em um número próximo ao triplo das empresas de confecções tomadoras. Segundo as faccionistas entrevistadas, é comum uma empresa contratar várias facções para executar o trabalho e as tentativas de negociação do preço fracassam diante do grande número de costureiras que aceitam trabalhar pelo preço determinado pelo empresário.

A fragilidade do poder de negociação poderia ser superada através da criação de uma associação de defesa de seus interesses. Mas, realizando o trabalho de forma isolada, distantes de outras companheiras e dispersas pela cidade, a organização de uma entidade representativa está longe de se concretizar. Sequer conhecem esta possibilidade. A associação poderia tornar-se um instrumento de valorização profissional, situação que é pouco percebida por estas costureiras, que entendem seu trabalho não como uma forma de realização profissional, mas como uma contribuição para as despesas domésticas. A desvalorização de seu trabalho se manifesta também pelo fato de só poder ser realizado após cumprirem com suas obrigações domésticas.

A jornada de trabalho das entrevistadas é, em média, de 12 horas por dia ou enquanto agüentar, conforme afirmou uma costureira. O trabalho remunerado é intercalado com as tarefas domésticas, e, nas épocas de maior pico produtivo, trabalham também aos sábados e domingos. Este prolongamento de trabalho torna-se vantajoso para os empresários que não arcam com os tradicionais ônus das horas extras, cujo adicional legal no Brasil é de, no mínimo $50 \%$, exigido nas relações assalariadas reconhecidas. Dessa forma, o trabalho domiciliar, embora mascarado como autônomo, torna-se uma expressão de precariedade, sem a regulamentação das jornadas de trabalho e outros direitos. A fixação da jornada diária de trabalho, em média 8 horas, cuja conquista foi precedida de um processo de lutas dos trabalhadores, encontra-se na atualidade em retrocesso, pois muitas atividades não têm mais jornadas de trabalho definidas. 
Contudo, apesar das longas jornadas serem prejudiciais à saúde, ao convívio social e ao lazer, as costureiras demonstraram uma certa passividade nesta condição.

Pôde-se verificar, ao longo das entrevistas, que estas costureiras apresentam algumas rejeições quanto ao trabalho fabril, especialmente quanto à separação entre local de trabalho e de moradia, pois há também a perda de controle sobre seu tempo. Entretanto, no trabalho a domicílio, o que ocorre é uma falso sentimento, por parte das entrevistadas, de controle do seu tempo. Nesta situação ocorre um constrangimento do uso do tempo, pois as mulheres estão submetidas a uma longa jornada de trabalho, pela intensificação e ampliação dessa jornada, confundindo-se os espaços da reprodução social e da atividade econômica. Como diz Betânia Ávila (2002, p. 40), "existem pessoas inseridas em processos de trabalho nos quais não há uma forma de regular o tempo, onde os tempos da reprodução e da produção são perversamente fundidos e as jornadas de trabalho se dão de formas contínuas".

Esta questão está bem presente no cotidiano dessas trabalhadoras, pois todas se queixaram da ausência de férias, afirmando algumas que, quando não estão trabalhando, não significa que estão descansando, pois estão sempre disponíveis para o trabalho e que gostariam de ter férias como os demais trabalhadores. Trata-se de um trabalho precário, inseguro, com remuneração intermitente, ausência de garantias trabalhistas e descontinuidade de inserção no mercado de trabalho.

Quase todas essas costureiras, antes de ingressarem no trabalho domiciliar, trabalhavam em fábricas, mas o trabalho formal foi abandonado, de acordo com as entrevistadas, devido à necessidade de cuidar dos filhos e das tarefas domésticas.

Conforme afirma Leite (2004), de um lado, encontra-se o empregador que busca flexibilidade, redução de custos e transferência 
de riscos, em um contexto de elevada competitividade; de outro, estão as costureiras, mulheres, mães e esposas que acumulam a dupla função: da responsabilidade do cuidado dos afazeres do lar e da contribuição para o seu sustento. Ramalho (1997) chama a atenção para este tipo de situação, citando pesquisas realizadas em países europeus, onde trabalhadores em domicílios aceitam baixos salários e condições de trabalho precárias, demanda irregular, extensa jornada de trabalho, entre outros fatores que caracterizam este tipo de atividade produtiva, destacando também a desinformação sobre os direitos legais.

\section{Conclusão}

O desenvolvimento da indústria da confecção em Divinópolis, ao longo das décadas de 1980 e 1990, permitiu uma maior inserção da mulher no mercado de trabalho, mas de maneira informal e flexível. A reestruturação pela qual este segmento passa faz com que suas trabalhadoras retornem à segregação de suas casas, acumulando tarefas domésticas e trabalho remunerado precariamente. Entretanto, conforme indicam os diferentes estudos, não se trata de um fenômeno exclusivo deste segmento, mas das tendências mais gerais do processo de reestruturação produtiva. Neste sentido, afirma Neves (2000), a utilização da mão-de-obra feminina no processo de flexibilização e modernização produtiva ocorre através de jornadas parciais, contratos por tempo determinado, trabalhos a domicílio, utilizando-se uma vez mais da qualificação informal adquirida pelas mulheres no trabalho doméstico, mas sem nenhuma forma real de valorização do trabalho feminino. Pelo contrário, elas estão submetidas a condições de trabalho precárias e inseguras, marcadas por baixos salários, pela realização de várias tarefas simultâneas e flexíveis - ocasionando intensificação do ritmo do trabalho - e pela perda dos direitos legais. 
O enfraquecimento da regulação do trabalho e dos direitos trabalhistas possibilitam a multiplicação dessas atividades, gerando extensão da jornada de trabalho e uma extensão /interação entre espaço doméstico e espaço produtivo. Neste contexto, o uso do tempo produtivo/econômico e o tempo para reprodução passam por transformações, pois a jornada de trabalho - que ocorre continuamente - funde estes dois tempos, reforçando mais ainda, na atualidade, a dupla jornada de trabalho feminina.

Conforme demonstraram vários estudos envolvendo a reestruturação produtiva e gênero, a mulher está ampliando sua participação no mercado de trabalho, mas, em alguns setores, esta inserção se caracteriza por uma maior precarização, reforçando situações históricas de discriminação na sociedade.

Gender, flexibility and precarization: the domestic labour at readymade article clothing industry

Abstract: The global economy and its fast processes of changing and the productive reestructuration turned gender relations at work. The increasing entrance of female contingent at labour market, besides the visibility that engenders at private sphere, shows a set of new women experiences at market and in society. In the latest few years, the flexible dynamic productive process has brougt on a significative growing of informal work, in a process caractherized by its heterogeneity and also by its sistemic interaction between formal and informal sector. The aim of this paper is to analyse the domestic labour developed by women for ready-made article clothing in a city of medium size at Minas Gerais. The weakness of labour regulation and social rights made possible the multiplication of these precarized activities that creates flexible labour contracts, labour conditions, day's journey and an extension/interaction between private/domestic space and productive/economic space.

Keywords: gender relations, productive reorganization, flexibility, precarization. 


\section{Referências bibliográficas}

ABRAMO, Laís. Um olhar de gênero: visibilizando precarizações ao longo das cadeias produtivas. In: ABRAMO, Laís; ABREU, Alice de Paiva (Org.). Gênero e trabalho na Sociologia latinoamericana. São Paulo: Alast, 1998. p. 39-61.

ABREU, Alice de Paiva; SORJ, Bila. Trabalho a domicílio e relações de gênero: as costureiras externas do Rio de Janeiro. In: ABREU, Alice de Paiva; SORJ, Bila (Org.). O trabalho invisivel: estudos sobre trabalhadores a domićlio no Brasil. Rio de Janeiro: Rio Fundo, 1993. p. 49-61.

ARAÚJO, Ângela M. Carneiro; AMORIM, Elaine Regina Aguiar. Redes de subcontratação e trabalho a domicílio na indústria de confecção: um estudo na região de Campinas. Cadernos Pagu, Campinas, n.17/18, p. 267-310, 2001/2002.

ÁVILA, Maria Betânia. O tempo e o trabalho das mulheres. In: COSTA, Ana Alice, et al. Um debate crítico a partir do feminismo: reestruturação produtiva, reprodução e gênero. São Paulo: CUT, 2002. p. 37-46.

BORGES, Ângela; DRUCK,Graça. Terceirização: balanço de uma década. Caderno CRH, Salvador, n. 37, p. 111-139, jul./dez. 2002

CARVALHO NETO, Antônio; NEVES, Magda de Almeida; JAYME, Juliana Gonzaga. Setor informal: abrigo para o trabalho infantil. In: MARQUES, M. Elizabeth; NEVES, Magda de Almeida; CARVALHO NETO, Antônio. Trabalho infantil: a infância roubada. Belo Horizonte: PUC Minas, Instituto de Relações do Trabalho, 2002. p. 79-98.

CASTEL, Robert. As metamorfoses da questão social: uma crônica do salário. Petrópolis: Vozes, 1998.

CHARMES, Jacques. O setor informal na África: um crescimento que não significa marginalização. Ensaios FEE, Porto Alegre, v. 18, n. 2, p. 64-99, jul. 1997. 
DRUCK, Graça. Flexibilização e precarização: formas contemporâneas de dominação do trabalho. Caderno $C R H$, Salvador, n. 37, p. 11-22, jul./dez, 2002.

FILGUEIRAS, Luiz A. M.; DRUCK, Graça; AMARAL, Manoela Falcão. O conceito de informalidade: um exercício de aplicação empírica. Caderno CRH, Salvador, v. 17, n. 41, p. 211-229, maio/ago. 2004.

FUNDAÇÃO CARLOS CHAGAS. Séries históricas. Disponível em: $<$ http://www.fcc.org.br/mulher/index.html $>$ Acesso em: 13 jul. 2005.

HIRATA, Helena. Reestruturação produtiva, trabalho e relações de gênero. Revista Latino-Americana de Estudios del Trabajo, São Paulo, v. 4, n. 7, p. 5-17, 1998.

HIRATA, Helena; PRÈTECEILLE, Edmond. Trabalho, exclusão e precarização socioeconômica: o debate das ciências sociais na França. Caderno CRH, Salvador, n. 37, p. 47-80, jul./dez. 2002.

LAUTIER, Bruno. L'economie informelle dans le Tiers Monde. Paris: La Découverte, 1994.

LAVINAS, Lena; SORJ, Bila. O trabalho a domicílio em questão: perspectivas brasileiras. In: ROCHA, Maria Isabel Baltar (Org). Trabalho e gênero: mudanças, permanências e desafios. São Paulo: Ed. 34, 2000. p. 211-236.

LEITE, Maria de Paula. Tecendo a precarização: gênero, trabalho e emprego na indústria de confecções de São Paulo. In: ENCONTRO ANUAL DA ANPOCS, 28, 2004, Caxambu, MG. [Anais]. CD- ROM. 2004. p. 1-30.

NEVES, Magda de Almeida. As novas configurações do trabalho: diversidade, precarização e dominação. In: ZEBALLOS, Eliseo; SANTOS, José Vicente Tavares; FIGUEREDO, Dario (Org). América Latina: hacia uma nueva alternativa de desarrollo. Arequipa, Peru: Unsa, 2004. p. 186-199. 
NEVES, Magda de Almeida. Cadeia automotiva: flexibilidade, precarização e relações de gênero. Trabalho e Educação, Revista do NETE/ $U F M G$, Belo Horizonte, n. 8, p. 90-110, jan./jul. 2001.

. Reestruturação produtiva, qualificação e relações de gênero. In: ROCHA, Maria Isabel Baltar (Org.). Trabalho e gênero: mudanças e desafios. São Paulo: Ed. 34, 2000. p. 171-185.

PEDROSA, Célia Maria. Limites e potencialidades do desenvolvimento local: a indústria da confecção de Divinópolis. 2005. Dissertação (Mestrado em Ciências Sociais) - Pontifícia Universidade Católica de Minas Gerais, Belo Horizonte.

RAMALHO, José Ricardo. Precarização do trabalho e impasses da organização coletiva no Brasil. In: ANTUNES, Ricardo et al. Neoliberalismo, trabalho e sindicatos: reestruturação produtiva no Brasil e na Inglaterra. São Paulo: Boitempo, 1997. p. 85-113.

SILVA, Lorena Holzmann da. Trabalho a domícilio. In: CATTANI, A. D. (Org.) Trabalho e tecnologia: dicionário crítico. Petrópolis: Vozes, 2001. p. 275-278.

ULYSSEA, Gabriel. Informalidade no Mercado de trabalho brasileiro: uma resenha da literatura. Rio de Janeiro: IPEA. Disponível em: $<$ http://www.ipea.gv.br> Acesso em: 20 jul. 2005. 